\title{
LIFE e formação de professores: experiências no Colégio de Aplicação/UFRGS ${ }^{1}$
}

\author{
Taís Cristine Ernst Frizzo* \\ Felipe Lohmann Arend** \\ Fernanda Britto da Silva** \\ Rosane Nunes Garcia*** \\ Victor João da Rocha Maia Santos****
}

\section{Resumo:}

Este trabalho apresenta experiências desenvolvidas no programa Laboratório Interdisciplinar de Formação de Educadores (LIFE) do Colégio de Aplicação/UFRGS. As atividades foram estruturadas em forma de oficinas desenvolvidas para os alunos das licenciaturas em período de estágio docente, para bolsistas participantes do PIBID e para professores da rede pública de ensino. Desde 2013, cerca de 95 professores (formados e em formação) passaram por formações interdisciplinares na área das Ciências da Natureza. Os resultados indicam que houve contribuições para a formação inicial e continuada dos participantes, relatadas pelos próprios, como as dinâmicas realizadas nas oficinas, o incremento de novos conhecimentos, a reflexão em relação à educação e às atividades práticas, o compartilhamento de experiências e a compreensão a respeito da interdisciplinaridade.

\section{Palavras-chave:}

Formação de professores. Ensino de Ciências. Laboratório Interdisciplinar de Formação de Educadores.

\footnotetext{
Abstract:

This work presents experiences developed in the program Interdisciplinary Laboratory for Educators Training (LIFE) of the Colégio de Aplicação/UFRGS. The activities were structured in the form of workshops developed for undergraduate students in the teaching internship period, for scholarship

* Professora doutora da área de Ciências e Biologia do Colégio de Aplicação da Universidade Federal do Rio Grande do Sul. E-mail: tais.frizzo@ufrgs.br. ORCID iD: http://orcid.org/0000-0001-8934-7518.

** Professor doutor da área de Ciências e Biologia do Colégio de Aplicação da Universidade Federal do Rio Grande do Sul. E-mail: felipe.arend@ufrgs.br. ORCID iD: http://orcid.org/0000-0001-9148-8555.

** Professor doutor da área de Ciências e Biologia do Colégio de Aplicação da Universidade Federal do Rio Grande do Sul. E-mail: felipe.arend@ufrgs.br. ORCID iD: http://orcid.org/0000-0001-9148-8555.

${ }^{* * *}$ Professora doutora da área de Ciências e Biologia do Colégio de Aplicação da Universidade Federal do Rio Grande do Sul. E-mail: fernanda.britto@ufrgs.br. ORCID iD: http://orcid.org/0000-0002-0197-3694.

**** Professora doutora da área de Ciências e Biologia do Colégio de Aplicação da Universidade Federal do Rio Grande do Sul. E-mail: rosane.garcia@ufrgs.br. ORCID iD: http://orcid.org/0000-0002-4647-6245.

***** Professor doutor da área de Química do Colégio de Aplicação da Universidade Federal do Rio Grande do Sul. E-mail: victor.jrms@gmail.com. ORCID iD: http://orcid.org/0000-0003-2274-3756.

1. Agradecemos à Coordenação de Aperfeiçoamento de Pessoal de Nível Superior (CAPES), aos professores oficineiros do Colégio de Aplicação, ao LIFE Casa de Ofícios da Faculdade de Educação da UFRGS, aos demais oficineiros e aos participantes do projeto.
} 
holders participating in PIBID and for public school teachers. Since 2013, about 95 teachers (graduates and non-graduates) have undergone interdisciplinary training in the area of Natural Sciences. The results indicate that there were contributions to the initial and continued training of the participants, reported by themselves, such as the dynamics carried out in the workshops, the increase in new knowledge, the reflection in relation to education and practical activities, the sharing of experiences and understanding about interdisciplinarity.

\section{Keywords:}

Teacher education. Science teaching. Interdisciplinary Laboratory for Educators Training.

\section{Introdução}

O sistema educacional brasileiro está centrado em um ensino dividido em várias áreas que integram pouco os diferentes saberes entre si e que mantêm a compartimentalização dos conhecimentos. De outro lado, acreditamos que buscar uma perspectiva mais integrada poderia facilitar a integração entre as áreas e a produção de aprendizagens significativas para o educando.

Esse sistema repete-se nos cursos de licenciatura, gerando profissionais que possuem dificuldade em incorporar, às suas atividades pedagógicas, a interdisciplinaridade, o uso das tecnologias e de produzir inovações capazes de modificar os problemas existentes na área da Educação, como o desinteresse, a repetência e evasão escolar em grande escala. Os processos educacionais necessitam de experiências alternativas que propiciem formação de cidadãos capazes de integrarem-se e atuarem nos processos de mudanças dos seus espaços sociais, articulando o conhecimento formal com as demandas de um mundo em constante transformação.

As Ciências da Natureza, de uma forma geral, têm apresentado avanços significativos, demonstrando inovações pertinentes ao processo de ensino-aprendizagem da área. O conhecimento que vem sendo construído nos diferentes campos do conhecimento científico, indiscutivelmente, se constituem através da inter, multi e transdisciplinaridade, levando a resultados que impactam diretamente na sociedade. Entretanto, o cenário que se apresenta, principalmente nos países em desenvolvimento, é uma disparidade entre os avanços científicos e tecnológicos e a educação.

A educação científica e o ensino das Ciências da Natureza têm sido compreendidos como essenciais para as nações já há muitas décadas. Historicamente é possível verificar que o ensino de Ciências assume importância, principalmente a partir da década de 1950 do século passado quando, em função da disputa entre Estados Unidos e União Soviética, ficou evidenciada a necessidade de investir no ensino de Ciências para superar o cenário que se apresentava. Os currículos para o ensino de Ciências passam então a ser repensados, buscando fortalecer o ensino nas escolas, além de também promover o interesse das crianças e jovens pela ciência, visando que cada vez mais pessoas buscassem as carreiras científicas.

Mas para que as propostas educacionais sejam efetivamente reformuladas e possam melhorar a qualidade do ensino das Ciências da Natureza, é importante que as professoras e os professores recebam formação que os tornem aptos a integrarem, nos seus planejamentos, objetivos de aprendizagem que contemplem o desenvolvimento da alfabetização/letramento científico, da interdisciplinaridade e de metodologias inovadoras de ensino.

A formação de professores para o ensino das Ciências da Natureza tem sido um campo de estudos para diferentes autores, trazendo conhecimento a respeito da didática das Ciências, além de apontarem para a necessidade de um processo de reformulação da forma de ensinar (CARVALHO; GIL-PÉREZ, 2011; KRASILCHIK; MARANDINO, 2007; SASSERON; SOUZA, 2017; CACHAPUZ et al., 2011; SANTOS; AULER, 2011; DELIZOICOV; ANGOTTI; PERNAMBUCO, 2011). Mas a tarefa não é simples, muitas vezes o professor julga que somente saber o conteúdo é o principal para bem ensinar, esquecendo que este conhecimento precisa ser compartilhado de forma contextualizada e que dialogue com a realidade do estudante. 
Assim, iniciativas que busquem desenvolver a formação inicial e continuada de professores, possibilitando que cada vez mais possam reformular a sua maneira de ensinar, podem contribuir de forma significativa com a qualificação do ensino das Ciências da Natureza. Carvalho e Gil-Pérez (2011) apontam que frequentemente nos cursos de formação de professores dá-se muita ênfase para a aprendizagem dos conteúdos de Ciências, deixando para segundo plano a construção de outros saberes que são importantes para evitar o ensino puramente conceitual da ciência. Os autores destacam que os professores precisam aprender sobre a história das Ciências, as orientações metodológicas empregadas na construção dos conhecimentos científicos, conhecer as interações entre ciência, tecnologia e sociedade, ter algum conhecimento dos desenvolvimentos científicos recentes e suas perspectivas e saber selecionar conteúdos adequados que sejam atuais e acessíveis aos estudantes (CARVALHO; GIL-PÉREZ, 2011). Professores formados a partir destas indicações teriam plenas condições de incluírem em seus planejamentos aulas capazes de desenvolver a alfabetização/letramento científico, além de permitir a articulação dos conhecimentos de forma mais interdisciplinar.

A partir do exposto acima, apresentamos este trabalho na forma de relato de algumas das experiências desenvolvidas no Laboratório Interdisciplinar de Formação de Educadores (LIFE) do Colégio de Aplicação (CAp) da Universidade Federal do Rio Grande do Sul (UFRGS), com o objetivo de compartilhar as experiências realizadas na formação inicial e continuada de professores, a fim de que sirvam como material inspirador para o desenvolvimento de práticas pedagógicas nessa área.

O programa Laboratório Interdisciplinar de Formação de Educadores (LIFE) foi organizado pela Coordenação de Aperfeiçoamento de Pessoal de Nível Superior (CAPES), em consonância com os objetivos da Diretoria de Formação de Professores da Educação Básica (DEB), sendo lançado em 2012. O programa busca "[...] ampliar o acesso dos cursos de formação docente aos modernos recursos tecnológicos e de inovação educacional", sendo essa uma necessidade "oriunda do contexto de desafios e possibilidades originados a partir do desenvolvimento cada vez mais acelerado da tecnologia e das complexas mudanças dele advindas [...]" (BRASIL, 2013).

Os laboratórios se caracterizam por constituírem espaços de uso comum das licenciaturas nas dependências de instituições públicas de Ensino Superior, a fim de promover a interação entre diferentes cursos de formação de professores e de incentivar o desenvolvimento de metodologias voltadas para a inovação das práticas pedagógicas, a formação interdisciplinar dos estudantes de licenciatura, a elaboração de materiais didáticos de caráter interdisciplinar e o uso das Tecnologias da Informação e Comunicação (TICs)².

O LIFE do Colégio de Aplicação da UFRGS, ou LIFE/CAp/UFRGS, está inserido em uma unidade de educação básica, possibilitando a participação em atividades de caráter prático que favoreçam o desenvolvimento da educação científica. Além disso, atua em parceria com outras unidades da Universidade, incluindo a Faculdade de Educação (FACED) da UFRGS. O LIFE na UFRGS foi inicialmente estruturado em parceria com a Faculdade de Educação e o Colégio de Aplicação, nos projetos integrados denominados LIFE Casa de Ofícios - FACED e LIFE Colégio de Aplicação. Posteriormente agregou-se ao LIFE/UFRGS o Consciência e Arte, sediado na Escola de Educação Física, Fisioterapia e Dança (ESEFID) da UFRGS.

O objetivo geral do LIFE/CAp/UFRGS é contribuir com a formação inicial e continuada de educadores, através do oferecimento de atividades de caráter teórico-prático que estimulem as práticas pedagógicas interdisciplinares, tendo como público-alvo professores em formação inicial e continuada, privilegiando as instituições da rede pública de ensino.

A organização das atividades de formação privilegia o oferecimento de oficinas, que são atividades de caráter teórico-prático e buscam promover uma reflexão à respeito: a) das práticas pedagógicas nas diferentes áreas de conhecimento; b) da possibilidade do trabalho interdisciplinar como elemento transformador do currículo na educação básica.

Neste trabalho optamos por apresentar três resultados das experiências realizadas no programa, além de discutir questões mais gerais, observadas ao longo do desenvolvimento do LIFE/CAp/UFRGS.

2. Informações disponíveis em: https://www.capes.gov.br/educacao-basica/life. Acesso em: 28 maio 2019. 


\section{Metodologia}

Com a finalidade de atender os objetivos do projeto LIFE, o LIFE/CAp/UFRGS estruturou as suas atividades através de oficinas que são desenvolvidas para os alunos das licenciaturas em período de estágio docente, para bolsistas participantes do PIBID e para professores da rede pública de ensino.

As atividades interdisciplinares nas oficinas LIFE/UFRGS se propõem a criar um espaço interativo para a formação docente, viabilizando uma experiência inicial aos professores e aos estudantes para a perspectiva interdisciplinar, já exaustivamente analisada e definida como fundamental para a formação de indivíduos críticos atuantes na sociedade. Dessa forma, são ministradas, preferencialmente, por professores de áreas de conhecimento distintas e/ou abordam temas interdisciplinares.

O LIFE do Colégio de Aplicação da UFRGS, sediado no Campus do Vale no município de Porto Alegre, Rio Grande do Sul, vem atuando desde 2013 e já atendeu cerca de 150 estudantes (professores em formação inicial) e professores em formação continuada, todos certificados através da Extensão Universitária.

Ao longo do projeto, são promovidas pelos professores do Colégio de Aplicação da UFRGS ações integradas entre diferentes áreas do conhecimento, seja pela escolha dos temas abordados, seja pelo estabelecimento de parcerias com outras unidades. Os professores regentes das disciplinas de estágio docente da FACED/UFRGS também já participaram das atividades, o que permitiu a articulação das temáticas desenvolvidas nas oficinas com a orientação dos planejamentos das aulas do estágio. As oficinas desenvolvidas pelo grupo de professores do Colégio de Aplicação e demais colaboradores (professores em formação nos cursos de mestrado e doutorado e participantes de outras instituições) têm trabalhado conceitos que relacionam especialmente as área da Ciências da Natureza, assim como também com áreas como a Veterinária, a Antropologia, a Geografia e a Arte, entre outras.

No Quadro 1 foram organizadas as oficinas oferecidas entre 2013 e 2018 pelo projeto LIFE/CAp/ UFRGS. Nota-se que doze oficinas foram reeditadas ao menos duas vezes, ampliando as possibilidades de participação dos estudantes e professores. Os critérios determinantes para organizar o oferecimento das oficinas foram as demandas identificadas nas avaliações das atividades e as possibilidades de participação dos professores ministrantes.

Quadro 1 - Oficinas realizadas pelo LIFE/CAp/UFRGS entre 2013 e $2018^{3}$

\begin{tabular}{|l|c|c|c|}
\hline Nome da Oficina & $\begin{array}{c}\text { Datas de } \\
\text { realização (ano) }\end{array}$ & $\begin{array}{c}\text { Áreas do } \\
\text { conhecimento } \\
\text { relacionadas }\end{array}$ & $\begin{array}{c}\text { Parceria com } \\
\text { outras unidades ou } \\
\text { instituições }\end{array}$ \\
\hline Conhecendo melhor o DNA & $\begin{array}{c}2013,2014, \\
2016,2017\end{array}$ & Biologia e Química & \\
\hline $\begin{array}{l}\text { Produção de Histórias em Quadrinhos para } \\
\text { divulgação científica em Ciências da Natureza }\end{array}$ & $\begin{array}{c}2013,2014, \\
2016,2017\end{array}$ & Biologia e Química & \\
\hline Morro Santana & 2013 & Biologia e Geografia & \\
\hline Guarda responsável & $2013,2016,2017$ & Biologia e Veterinária & \\
\hline $\begin{array}{l}\text { Construindo o entendimento sobre os } \\
\text { processos enzimáticos }\end{array}$ & 2013,2014, & Biologia e Química & \\
\hline $\begin{array}{l}\text { A subjetividade dos sujeitos do espaço } \\
\text { escolar: uma proposta interdisciplinar }\end{array}$ & 2016,2017 & Educação & $\begin{array}{c}\text { PPG Educação em } \\
\text { Ciências/UFRGS }\end{array}$ \\
\hline Escola Espaço Educador Sustentável & 2016 & $\begin{array}{c}\text { Professoras dos } \\
\text { municípios de } \\
\text { São Leopoldo e } \\
\text { Porto Alegre }\end{array}$ \\
\hline Alimentação Funcional & 2016 & Biologia, Educação & \\
\hline
\end{tabular}

3. Em 2015 não houve oferecimento de oficinas porque o programa passou por uma reestruturação e o foco foi na construção do regimento do LIFE/UFRGS. 


\begin{tabular}{|c|c|c|c|}
\hline Nome da Oficina & $\begin{array}{c}\text { Datas de } \\
\text { realização (ano) }\end{array}$ & $\begin{array}{c}\text { Áreas do } \\
\text { conhecimento } \\
\text { relacionadas }\end{array}$ & $\begin{array}{c}\text { Parceria com } \\
\text { outras unidades ou } \\
\text { instituições }\end{array}$ \\
\hline O ensino de evolução e a história da biologia & 2016, 2017 & Biologia & PPG Genética/UFRGS \\
\hline $\begin{array}{l}\text { Atividades Disparadoras para Iniciação } \\
\text { Científica no } 6 .^{\circ} \text { e } 7 .^{\circ} \text { ano }\end{array}$ & 2016,2017 & $\begin{array}{l}\text { Diversas áreas do } \\
\text { Ensino Fundamental }\end{array}$ & \\
\hline Trabalhando com bactérias no ensino básico & 2016,2017 & Biologia & $\begin{array}{c}\text { Colégio Estadual } \\
\text { Florinda Tubino } \\
\text { Sampaio }\end{array}$ \\
\hline Vamos para o pátio? & 2016,2017 & $\begin{array}{l}\text { Biologia, Geografia, } \\
\text { Antropologia }\end{array}$ & \\
\hline Observação de aves na escola & 2017,2018 & $\begin{array}{c}\text { Biologia, Física e } \\
\text { Química }\end{array}$ & $\begin{array}{c}\text { Colégio Estadual } \\
\text { Florinda Tubino } \\
\text { Sampaio }\end{array}$ \\
\hline $\begin{array}{l}\text { A integração das Ciências Exatas e da } \\
\text { Natureza: compartilhando possibilidades }\end{array}$ & 2017 & $\begin{array}{l}\text { Química, Biologia, } \\
\text { Física }\end{array}$ & \\
\hline $\begin{array}{l}\text { Escolas e Unidades de Conservação: } \\
\text { tecendo aproximações }\end{array}$ & 2018 & $\begin{array}{c}\text { Biologia, } \\
\text { Antropologia }\end{array}$ & \\
\hline $\begin{array}{l}\text { Alfabetização Científica nas aulas de } \\
\text { Ciências da Natureza }\end{array}$ & 2018 & $\begin{array}{l}\text { Química, Biologia, } \\
\text { Física }\end{array}$ & \\
\hline Ensinando Ciências com Arte & 2018 & Biologia e Artes & \\
\hline Oficinas Licenciatura Educação do Campo & 2018 & Biologia e Química & \\
\hline Na Trilha da Educação Ambiental & 2018 & $\begin{array}{l}\text { Biologia, Geografia, } \\
\text { Educação }\end{array}$ & \\
\hline
\end{tabular}

Fonte: Elaborado pelos autores.

\section{Resultados e discussão}

Como resultados do trabalho do LIFE/CAp/UFRGS, observam-se dois fatores aqui destacados: a interação entre diferentes áreas do conhecimento e entre diferentes unidades da Universidade ou instituições, o que favorece a abordagem interdisciplinar das atividades oferecidas por meio das oficinas.

Todas as oficinas foram organizadas a partir de uma perspectiva interdisciplinar, por entendermos que a construção do conhecimento integrado e a interação entre diferentes áreas de conhecimento, favorece a compreensão do mundo de forma mais significativa. Além disso, sempre foi realizada a reflexão sobre a prática, através da coleta de informações com questionários de avaliação aplicados nos participantes das oficinas, além de reuniões avaliativas entre os oficineiros. Conforme Fazenda (2012, p. 25), citando Japiassú4:

Japiassú em seu estudo, coloca como indicação para efetivação dessa metodologia interdisciplinar uma nova espécie de cientista, o interdisciplinar. Esse tipo especial de profissional exige uma forma própria de capacitação, aquela que o torne participante do nascimento de uma "nova consciência" e de uma nova pedagogia, a baseada na comunicação; para tanto prevê instituições preparadas para esta forma diferenciada de capacitação docente. [...] Nossa pesquisa indica-nos o valor dos registros das situações vividas num trabalho interdisciplinar. Eles propiciam a indicação de aspectos de êxito e fracasso em trabalhos dessa natureza. O registro hoje nos parece, portanto, um dos pressupostos básicos para a realização de um trabalho interdisciplinar.

4. As primeiras reflexões sobre interdisciplinaridade no Brasil remetem à década de 1970. Fazenda (2012) destaca a produção de Japiassú e a publicação, em 1976, do livro Interdisciplinaridade e patologia do saber. 
Como resultado das avaliações periódicas, observamos que houve contribuição das atividades na formação inicial e continuada dos professores. Cabe indicar as referências, nas avaliações, sobre: a dinâmica de trabalho adotada nas oficinas, permitindo uma proximidade maior com os ministrantes, o que garantiu um olhar mais individual às necessidades dos participantes; o incremento de novos conhecimentos; a reflexão em relação à educação e às práticas em sala de aula, a fim de estimular um olhar mais atento aos educandos; o compartilhamento de experiências vividas por outros colegas de diferentes áreas de conhecimento; as compreensões a respeito da interdisciplinaridade e as noções de como aplicá-la na prática; a contribuição no sentido de repensar a educação, de ter novas ideias e ânimo para fazer diferente; o conhecimento sobre projetos de aprendizagem; e a aprendizagem de novos conceitos, ideias, estratégias pedagógicas e metodologias para a prática em sala de aula.

Partindo desses resultados gerais, passamos, nos tópicos a seguir, a apresentar os relatos de três experiências vivenciadas no LIFE/CAp/UFRGS.

\section{Vamos para o pátio?}

Os Estudos Baseados no Lugar (Placed Based Education) e a Educação ao Ar Livre (Outdoor Education) são referências que embasaram o objetivo da oficina "Vamos para o pátio?".

A Outdoor Education geralmente se refere às atividades de aprendizagem organizadas ao ar livre. Os programas de educação ao ar livre envolvem experiências locais ou viagem para outros lugares, baseadas nas vivências junto à natureza. Nesses momentos, são exploradas atividades nas quais os estudantes participam de uma variedade de desafios e ações ao ar livre, como caminhadas, escaladas, canoagem, cordas e jogos em grupo. A educação ao ar livre baseia-se em práticas de educação experiencial e de educação ambiental. Além disso, podem oferecer aos educadores uma maneira de pensar sobre a educação ao ar livre que transcende o foco do "eu" e dos "outros" para incluir as relações com o meio ambiente (NICOL, 2002).

A Placed Based Education (PBE), por sua vez, é pensada a partir do lugar, ou seja, busca dedicar-se às características e aos problemas locais da comunidade como base para o desenvolvimento das ações, compreendendo que o aprendizado está enraizado no que é local - a história, o ambiente, a cultura, a economia, a literatura e a arte de um lugar específico. Nesse sentido, pode dedicar-se a tratar de um espaço mais próximo dos estudantes, como o pátio escolar, o bairro, a cidade ou a atividades de interação com a comunidade. Ao mesmo tempo, trata-se de uma abordagem interdisciplinar, pois busca integrar conhecimentos de diferentes áreas. A PBE está relacionada ao bem-estar dos cidadãos, ao conhecimento e valorização dos lugares sociais e ecológicos que as pessoas habitam (GRUENEWALD, 2003). De acordo com o autor, busca de "[...] abraçar a experiência de ser humano em conexão com os outros e com o mundo da natureza e da responsabilidade de conservar e restaurar nossos ambientes compartilhados para as gerações futuras" (GRUENEWALD, 2003, p. 6). Para Resor (2010), os estudantes aprendem a ir além da aparência aparentemente óbvia das coisas e a explorar a natureza mutável da percepção individual e comunitária, desenvolvendo o pensamento crítico.

$\mathrm{Na}$ oficina proposta, a sala de aula se estendeu ao pátio escolar. Houve um momento de trabalho com as bases teóricas acima descritas, passando-se à exploração o pátio, a fim de reconhecer a escola como parte do ecossistema urbano em interação com os ecossistemas naturais do entorno. Para tanto, trabalhamos com o resgate do passado do local, desde uma abordagem geológica até a história humana, a presença de populações tradicionais e de fatos mais recentes; o estudo dos seres vivos e as características ambientais.

O Colégio de Aplicação/UFRGS está localizado no entorno de uma área destinada à implantação de uma unidade de conservação, o Refúgio de Vida Silvestre Morro Santana, em Porto Alegre, RS. $\mathrm{Na}$ escola, podemos observar uma vegetação característica e espécies da fauna características da região. O Morro Santana reúne um dos maiores potenciais de biodiversidade do município, compondo áreas verdes inseridas na malha urbana. A vegetação apresenta-se como um mosaico de tipos diferentes, o que favorece a diversidade da fauna e os processos ecológicos que ali ocorrem. Além disso, tem uma importância histórica, 
pois se acredita que tenha sido palco do surgimento de Porto Alegre, a partir da instalação da sesmaria de Jerônimo de Ornellas Menezes e Vasconcelos, no século XVIII (SOUZA, 2012).

Por localizar-se próximo à área preservada, há significativa presença de aves no pátio da escola, o que possibilitou uma atividade sobre esses animais. A proposta incluiu uma caminhada para observação das aves, com o apoio de guias de fauna e flora, binóculos e máquinas fotográficas e a apresentação de atividades realizadas com estudantes do Colégio de Aplicação, como o "Guia de Aves do CAp/UFRGS" e o "Ornitokut" (SILVA; FRIZZO, 2015).

Além desses aspectos, pudemos, na oficina, refletir sobre os problemas ambientais e sociais do local. A comunidade do entorno usa a área para realizar a coleta de chás e outras plantas, prática de atividades físicas, religiosas ou para fins de lazer. Os Kaingang fazem a coleta do cipó para seus trançados. Os principais problemas enfrentados são a disposição inadequada de lixo, a erosão provocada pela prática de motocross, a captura de animais silvestres, as queimadas dos campos, e as ocupações imobiliárias, tanto irregulares como regulares, que podem interferir no tamponamento da unidade de conservação.

Para encaminhar à ação prática naquele momento e com o objetivo de auxiliar a prática docente, encaminharam-se questões sobre o pátio escolar para os participantes, que buscaram pensar estratégias para suas escolas.

\section{Observação de Aves}

A oficina "Observação de Aves" é desenvolvida no entorno do espaço escolar do Colégio de Aplicação buscando explorar o ambiente local para o ensino de Ciências. As atividades construídas na oficina têm como objetivo explorar as possibilidades de ensino aprendizagem junto aos professores e estudantes das licenciaturas através da observação das aves e atividades correlatas.

As atividades são baseadas na teoria da Educação pela Pesquisa, que propõe o desenvolvimento de atividades de investigação em sala de aula como uma atitude cotidiana de ensino e aprendizagem. A partir do uso dos princípios pertinentes ao ato de pesquisar, em situações pedagógicas, o estudante é colocado como protagonista de suas aprendizagens, superando os processos de ensino e aprendizagem tradicionais (PRESTES et al., 2011). O objetivo do processo do educar pela pesquisa é que o aluno produza e não receba o conteúdo pronto.

Dessa forma, é desenvolvido na oficina o exercício de possibilitar ao sujeito a compreensão em relação ao processo de aprendizado dos seus alunos, desenvolvendo a capacidade de crítica, escrita, questionamento, explicação e argumentação (FRESCHI; RAMOS, 2009) nos estudantes do ensino básico.

As aves são a temática para a oficina pois despertam a empatia nas pessoas de diversas maneiras: colorido e arranjo da plumagem, vocalização, capacidade de voo, tamanho e anatomia do corpo. Dessa forma, as aves se encaixam no papel de facilitadores do entendimento dos processos biológicos sensibilizando as pessoas (BENITES; MAMEDE, 2008; COSTA, 2007). As aves também facilitam a proximidade das pessoas com a natureza, desmistificando possíveis aversões com outros animais como morcegos, lagartos, insetos ou anfíbios, favorecendo assim uma interação maior.

Atividades como a observação de aves, inseridas como estratégias para o ensino e aprendizagem de Ciências, podem desenvolver conhecimentos que adquiram valor como ferramenta de transformação, uma vez que contribuem para o desenvolvimento de um espírito crítico e favorecem uma atitude de compromisso diante das interações homem-ambiente.

A observação de aves visa a contribuir também com a desfragmentação e contextualização dos conteúdos, possibilitando a articulação entre teoria e prática, dentro do cotidiano e do contexto do aluno e de forma interdisciplinar, já que proporciona experiências vividas na relação direta do sujeito com o objeto, levando à produção de conhecimento em diversas áreas do conhecimento. 


\section{Produção de histórias em quadrinhos para divulgação científica em Ciências da Natureza}

As Ciências da Natureza são uma área do conhecimento onde a quantidade de imagens utilizadas pelos professores são inúmeras, tais como: modelos atômicos (Química), DNA (Biologia), empuxo (Física), entre outros conteúdos, são exemplos da utilização de imagens para facilitar o entendimento do aluno, principalmente no que se refere ao ensino básico.

Apesar de ainda não ter um conceito definitivo, o termo Divulgação Científica, conforme Bueno (2009, p. 162), compreende a “[...] utilização de recursos, técnicas, processos e produtos (veículos ou canais) para a veiculação de informações científicas, tecnológicas ou associadas a inovações ao público leigo", ou ainda, "[...] democratizar o acesso ao conhecimento científico e estabelecer condições para a chamada alfabetização científica. Contribui, portanto, para incluir os cidadãos no debate sobre temas especializados e que podem impactar sua vida e seu trabalho" (BUENO, 2010, p. 1).

Visto dessa maneira, a Divulgação Científica realiza a codificação e a transposição da linguagem dita científica para uma linguagem mais informal e popular, cujo objetivo seja de tornar o conteúdo/assunto mais acessível e inteligível.

Conforme Da Silva (2006, p. 54), “[a]tividades de divulgação científica surgiram junto com a própria ciência moderna", e qualquer ação nesse sentido sempre vai ter como enfoque o "reflexo de um modo de produção de conhecimento" (p. 57) que será chamado de "efeito-leitor", pois sugere de um lado o produtor do conhecimento científico, no caso o cientista e do outro, em oposição a este, "o sujeito interessado em atualização cultural, sem nenhum conhecimento sobre ciência” (p. 58). Dessa maneira, a produção do material a ser distribuído a esse tipo de leitor(a) deve levar em consideração alguns detalhes de diagramação para a finalização do produto até as mãos desse indivíduo.

Um dos grandes problemas da Divulgação Científica, foi a forma como os primeiros pesquisadores da área da Alfabetização Científica, davam extremo valor aos textos científicos, o que na atual realidade de ensino, prejudicou outras formas de leitura de gêneros textuais:

A alfabetização no sentido fundamental é sobre como os leitores lidam com o texto, sobre como eles usam os recursos do texto para determinar o que eles significam ou podem significar. A alfabetização científica deve incluir as estratégias interpretativas necessárias para lidar com o texto científico. (NORRIS; PHILLIPS, 2003, p. 231, tradução nossa).

Por esse motivo, Kress e Leeuwen (2006) fazem algumas observações: 1) a sociedade contemporânea é extremamente visual; logo, faz-se necessário que a educação formal ensine aos seus alunos habilidades na produção de textos multimodais capacitando-os para este tipo essencial de comunicação, para não produzir analfabetos visuais; 2) o meio educacional deve se movimentar em direção a uma nova alfabetização, baseada em imagens e design visual, mesmo que isto soe como uma ameaça ou um sinal de declínio da cultura ocidental, impondo-se a grupos sociais conservadores.

De acordo com Hosler (SCIENCE..., 2018), existem duas formas de a população ter acesso ao mundo da ciência, um deles é pela maneira tradicional e estática da educação formal em Ciências da Natureza (Biologia, Física e Química) e a outra maneira seria mais dinâmica e informal que é pela divulgação científica, utilizando o gênero textual quadrinhos, como uma mídia que serviria como uma espécie de ponte de acesso a esse conhecimento.

E na mesma linha de raciocínio, os quadrinhos são propícios a isto, porque, como sugere Vergueiro (2018), os quadrinhos podem auxiliar no ensino e na aprendizagem de crianças, jovens e adultos, em qualquer área de conhecimento, devido a seu aspecto simplificado, porém, extremamente lúdico de apresentar uma determinada informação.

A oficina de quadrinhos oferecida pelo LIFE em parceria com o CAp/UFRGS, teve e têm como objetivo, atualizar os docentes na utilização de uma outra forma de linguagem que, apesar de ainda ser muito ironizada no meio acadêmico de Ciências da Natureza, vem ganhando aos poucos espaço no 
ensino (SANTOS; GARCIA, 2017), pois de acordo com a proposta da Teoria Cognitiva da Aprendizagem Multimídia (TCAM), de forma geral, um indivíduo aprende melhor ao se utilizar conjuntamente, de palavras e de imagens (MAYER, 2001).

Então, o motivo de se utilizar o gênero textual quadrinhos na área de Ciências da Natureza é o fato de que é um suporte que pode ser utilizado tanto de forma impressa quanto online, e por ser um meio que facilita a divulgação científica, conforme os parâmetros dispostos por Zamboni (2001), que deve possuir as seguintes características: 1) ser direcionado a um público não científico, ou seja, leigo; 2) se abrir para o emprego de simplificações; 3) envolver o(a) leitor(a) com o conteúdo da informação; 4) recuperar ou favorecer informações latentes do(a) leitor(a); 5) evitar termos incompreensíveis, ou seja, não comuns para o público geral; 6) possuir informações segmentadas, fazendo com que o(a) leitor(a) seja encorajado(a) a ler o próximo capítulo/edição/volume.

Por esses motivos, o conhecimento na utilização de outros gêneros textuais pelo(a)s docentes, como no caso os quadrinhos, favorecem um maior arsenal de formas didáticas que possibilitam uma outra dimensão na forma de ensino-aprendizagem.

\section{Considerações finais}

As oficinas ministradas pelo LIFE/CAp/UFRGS buscaram possibilitar uma ampliação do leque de estratégias pedagógicas, bem como um aprofundamento teórico para os participantes. O mote foi valorizar a formação inicial e continuada de professores, oportunizando vivências que os auxiliem no cotidiano escolar.

Destacamos que o trabalho realizado proporcionou a interação entre diferentes áreas do conhecimento e entre diferentes unidades da Universidade ou instituições, por meio de professores e estudantes de graduação e de pós-graduação. Dessa forma, a abordagem interdisciplinar foi valorizada e ponto de partida para as propostas das oficinas.

Uma dificuldade observada ao longo do projeto foi a participação efetiva de um número menor em relação aos inscritos. Além disso, em muitos momentos os participantes relataram dificuldades relacionadas à disponibilidade de carga horária para a realização das oficinas. Embora os turnos e dias de oferecimento das oficinas tenham ocorrido em distintos momentos, os professores que atuam na rede estadual, em especial, não dispunham de tempo para sua formação, havendo colisão com os horários das turmas onde atuavam ou com o seu período de descanso e preparação pedagógica. Quanto aos alunos da graduação, não obtivemos respostas que pudessem embasar a falta de participação nas atividades.

Assim, esperamos que o trabalho possa ser ampliado, a fim de atender mais instituições e, por consequência, um número maior de professores em formação inicial e continuada.

\section{Referências}

BENITES, Maristela; MAMEDE, Simone Batista. Mamíferos e aves como instrumentos de educação e conservação ambiental em corredores de biodiversidade do Cerrado, Brasil. Mastozoología neotropical, Mendoza, v. 15, n. 2, p. 261-271, 2008.

BRASIL. COORDENAÇÃO DE APERFEIÇOAMENTO DE PESSOAL DE NÍVEL SUPERIOR (CAPES). Diretoria de Formação de Professores da Educação Básica. Relatório de Gestão LIFE. Brasília, DF: CAPES, 2013. Disponível em: http://uab.capes.gov.br/images/stories/download/bolsas/1892014-relatorio-LIFE.pdf. Acesso em: 28 maio 2019.

BUENO, Wilson Costa. Comunicação científica e divulgação científica: aproximações e rupturas conceituais. Informação \& Informação, Londrina, v. 15, n. esp. 1, p. 1-12, dez. 2010. Disponível em: http://www.uel.br/seer/index.php/ informacao/article/view/6585/6761. Acesso em: 27 maio 2020.

BUENO, Wilson Costa. Jornalismo científico: revisitando o conceito. In: VICTOR, Cilene; CALDAS, Graça; BORTOLIERO, Simone (org.). Jornalismo científico e desenvolvimento sustentável. São Paulo, SP: All Print, 2009. p. 157-178.

CACHAPUZ, Antonio et al. A necessária renovação do ensino das ciências. 3. ed. São Paulo: Cortez, 2011.

CARVAlHO, Ana Maria Pessoa de; GIL-PÉREZ, Daniel. Formação de professores de ciências: tendências e inovações. 10. ed. São Paulo: Cortez, 2011. 
COSTA, Ronaldo Gonçalves de Andrade. Observação de aves como ferramenta didática para Educação Ambiental. Revista Didática Sistêmica, Rio Grande, v. 6, p. 33-44, jul./dez. 2007.

DA SILVA, Henrique César. O que é divulgação científica? Ciência \& Ensino, Piracicaba, v. 1, n. 1, p. 53-59, dez. 2006. Disponível em: http://200.133.218.118:3536/ojs/index.php/cienciaeensino/article/download/39/98. Acesso em: 27 maio 2020.

DELIZOICOV, Demétrio; ANGOTTI, José André; PERNAMBUCO, Marta Maria. Ensino de Ciências: fundamentos e métodos. 4. ed. São Paulo: Cortez, 2011.

FAZENDA, Ivani Catarina Arantes. Interdisciplinaridade: história, teoria e pesquisa. 18. ed. Campinas: Papirus, 2012.

FRESCHI, Márcio; RAMOS, Maurivan Güntzel. Unidade de Aprendizagem: um processo em construção que possibilita o trânsito entre senso comum e conhecimento científico. Revista Electrónica de Enseñanza de las Ciencias, España, v. 8 , n. 1, p. 156-170, 2009

GRUENEWALD, David A. The Best of Both Worlds: a critical pedagogy of place. Educational Researcher, United States, v. 32, n. 4, p. 3-12, maio 2003.

SCIENCE Comics Can Save the World! | Jay Hosler | TEDxJuniataCollege. [S. l.: s. n.], 2018. 1 vídeo (19 min 53 s). Publicado pelo canal TEDx Talks.. Disponível em: https://youtu.be/feTCOfJkq18. Acesso em: 14 jun. 2019.

KRASILCHIK, Myriam; MARANDINO, Martha. Ensino de ciências e cidadania. 2. ed. São Paulo: Moderna, 2007.

KRESS, Gunther; LEEUWEN, Theo van. Reading Images: the grammar of visual design. 2. ed. New York: Taylor \& Francis Group, 2006.

MAYER, Richard E. Teoria Cognitiva de Aprendizagem Multimédia. In: MIRANDA, Guilhermina Lobato. Ensino online e aprendizagem multimédia. Lisboa: Relógio d’Água Editores, 2009. p. 207-237.

NICOL, Robbie. Outdoor Environmental Education in the United Kingdom: a conceptual framework of epistemological diversity and its educational implications. Canadian Journal of Environmental Education, Canada, v. 7, n. 2, p. 207-224, 2002

NORRIS, Stephen P.; PHILLIPS, Linda M. How literacy in its fundamental sense is central to scientific literacy. Science Education, New York, v. 87, n. 2, p. 224-240, 2003. Disponível em: https://www.researchgate.net/publication/227504884_ How_Literacy_in_Its_Fundamental_Sense_Is_Central_to_Scientific_Literacy. Acesso em: 24 nov. 2016.

PRESTES, Roseléia Ferreira; LIMA; Valderez Marina do Rosário; RAMOS, Maurivan Güntzel. Contribuições do uso de estratégias para a leitura de textos informativos em aulas de Ciências. Revista Electrónica de Enseñanza de las Ciencias, España, v. 10, n. 2, p. 346-367, 2011.

RESOR, Cynthia Williams. Place-Based Education: what is its place in the social studies classroom? The Social Studies, United States, v. 101, n. 5, p. 185-188, 2010.

SANTOS, Victor João da Rocha Maia; GARCIA, Rosane Nunes. A pesquisa sobre o uso dos quadrinhos no ensino das Ciências da Natureza apresentadas nos ENPECs de 1997 a 2015. In: ENCONTRO NACIONAL DE PESQUISA EM EDUCAÇÃO EM CIÊNCIAS, 11., 2017, Florianópolis. Anais eletrônicos [...]. Florianópolis: ABRAPEC, 2017. Disponível em: http://www.abrapecnet.org.br/enpec/xi-enpec/anais/resumos/R1921-1.pdf. Acesso em: 2 nov. 2017.

SANTOS, Wildson Luiz Pereira dos; AULER, Décio (org.) CTS e Educação Científica: desafios, tendências e resultados de pesquisa. Brasília, DF: Editora Universidade de Brasília, 2011.

SASSERON, Lúcia Helena; MACHADO, Vítor Fabrício. Alfabetização Científica na prática: inovando a forma de ensinar física. 1. ed. São Paulo: Editora Livraria da Física, 2017. (Série Professor Inovador).

SILVA, Cristiane Oliveira da; FRIZZO, Taís Cristine Ernst. O potencial pedagógico das aves no ensino de ciências: explorando propostas de abordagem em educação ambiental. In: ENCONTRO REGIONAL SUL DE BIOLOGIA, 7., 2015, Criciúma. Anais [...]. Criciúma: UNESC, 2015. p. 524-534. Tema: Da formação à prática no ensino de ciências e biologia: desafios a superar. Disponível em: http://www.unesc.net/portal/resources/files/497/ANAIS_REBIO_PARTEII-reduced\%20(1).pdf. Acesso em: 8 jun. 2016.

SOUZA, Nali de Jesus de. Breve história da cidade de Porto Alegre. Porto Alegre, 2012.

VERGUEIRO, Waldomiro. Uso das HQs no ensino. In: RAMA, Angela; VERGUEIRO, Waldomiro (org.). Como usar as histórias em quadrinhos na sala de aula. 4. ed. São Paulo: Contexto, 2018. p. 7-30.

ZAMBONI, Lilian Márcia Simões. Cientistas, jornalistas e a divulgação científica: subjetividade e heterogeneidade no discurso da divulgação científica. Campinas: Autores Associados, 2001.

Data de submissão: 02/06/2020

Data de aceite: $01 / 07 / 2020$ 